\title{
Sonic Artefacts: "Record Collecting" in the Digital Age
}

\author{
Chris Anderton \\ Southampton Solent University \\ chris.anderton@solent.ac.uk
}

\begin{abstract}
This article examines fan practices of record collecting in the digital environment. It examines two forms of fan practice that suggest a shift from the secondary involvement (Shuker 2010) of physical record collecting to a tertiary form predicated on the collection and distribution of digital music files. The first digital era practice involves the collection of unofficially released recordings of live music performances as not-for-bootlegs created and circulated by and between fans. The second involves the collection of music originally encoded in out-of-print, rare or private press vinyl and cassette releases. The fans and collectors involved in creating, distributing and/or collecting these various forms of digitized music are characterized as active and informal cultural intermediaries, who curate, organize, archive, discuss and circulate recordings and information. Their activities also raise questions about cultural memory, the provision of 'free labour', and the contested nature of copyright.
\end{abstract}

KEYWORDS: popular music, bootlegging, blogging, record collecting, fandom, copyright

\section{Introduction}

This article discusses how the fan practice of record collecting (Shuker 2010, 2014) has developed with the emergence of digital forms of communication and distribution since the turn of the millennium. It begins to address one of several questions raised by Mark Duffett in Understanding Fandom: "to what extent is collecting premised on the ownership of the collected item or their rarity value"? (2013: 179, emphasis in original). This is an important question for the study of music fandom, since there has been a marked shift in recent years towards an 
access model of distribution (Wikström 2012), in which consumers do not purchase physical or digital products, but listen to music through a variety of streaming services (such as YouTube, Spotify, Apple Music, Pandora, Deezer, Rdio; see Hu 2015; IFPI 2015; Nielsen 2014).

Record collecting has often been characterized as a form of commodity fetishism focused on the accumulation of physical artefacts and the development of specialized knowledge (Bennett and Rogers 2016; Shuker 2010, 2014; see also Pearce 1992, 1995, on collecting more generally). Shuker (2014: 168) refers to these activities as forms of "secondary involvement", typified by fans who do more than collect the core releases of an artist. Their engagement includes the collecting of rare or unusual releases (including singles, mispressings, and alternate packaging), in addition to unofficial bootleg live recordings, and the reading, collection or production of fanzines, biographies, discographies, reviews and so on which may be published in print or online. This contrasts with "primary" forms of fandom which are focused on "the persona and public life of a star" (ibid.), hence connected to their celebrity status. There may be crossovers between the primary and secondary forms of fandom. In this article I will discuss and explore a third form of fandom, which concerns not the collection of physical artefacts produced by the music industries (often classified as traditional collecting practice), but the collection and archiving of audio recordings as sonic artefacts: as digitized music files that are collected and distributed through the Internet.

The unofficial peer-to-peer and online distribution of sonic artefacts through the Internet as MP3 or other file formats has a long history (see David 2009) and is typically collated under the term music piracy, since the permission of the copyright owners has not been sought, nor financial recompense made to them for this online distribution. Such piracy is widespread and has been subject to a wide variety of legal and other responses by music industry organisations and state governments seeking to enforce copyright legislation (Anderton et al. 2013; Burkart 2010; David 2009; Klein et al. 2015; Marshall 2005). This is particularly the case for pre-release piracy where albums or tracks are leaked on to the Internet prior to their official release date. However, this article will focus on two particular forms of activity which connect most closely to traditional forms of record collecting in terms of the audio content that is being distributed; it aims to help open up debate regarding the limits and contradictions of copyright legislation in the US and Europe.

The first of these practices is the production and sharing of not-for-profit bootleg recordings of live music performances - in other words, those made by audience members themselves or taped off the radio, for which there is no current legitimate release from the music industries. Unlike the products of the official industries, there are no contractual agreements in place regarding the ownership of rights, nor is there any exploitation of copyright for financial gain. This latter point is in contrast to the commercial bootlegging sector which seeks to make financial gains from recordings that are illegitimately released (see Heylin, 1995; Marshall 2005). In the not-for-profit sector, we see fans searching for the highest quality and most complete recordings of shows, which may then be remastered and distributed for free by what I term "pseudo-record labels". These pseudorecord labels act as brands in much the same way as the commercial sector: 
helping to establish a brand identity and reputation based around particular artists or kinds of music, and as an indicator of quality (Wall 2013: 124). The fans involved in these labels take on roles parallel to those seen in the commercial recording companies: sourcing and mastering recordings, designing and creating artwork, track lists and liner notes, and distributing the music in various forms though here, all is managed free of charge. Artwork created by fans for these projects typically carries phrases such as "never sell or buy - trade freely", and those involved sometimes characterize themselves as competing with commercial bootleg companies which are deemed unethical because they sell for profit (Anderton 2006; Marshall 2003, 2005).

The second practice to be discussed is the sharing of rare and difficult to find recorded music. This is music that was released in the past, but is now no longer available to purchase or stream as a physical or digital product from a legitimate source. In this sense it lies outside of the "long tail" (Anderson 2006) of the digital marketplace, which presupposes a virtual warehouse of unlimited capacity where recordings can be stored on Internet servers and consumed even in very small quantities: a situation that is uneconomic with regard to physical releases. The only legitimate availability of this material is as physical copies sold through second-hand record stores, charity shops, car boot sales and record fairs, or their online equivalents such as eBay, MusicStack, Eil.com and Discogs. As will be seen later, the tensions and contradictions of copyright law are highlighted by the legal distinctions that are made between the sale of second-hand physical products, and the free distribution of the audio content of those products online. The music discussed in this article includes that found on privately released vinyl and cassette albums, EPs and singles which were originally manufactured in relatively small quantities and are now regarded as rare (to varying extents) by traditional record collectors. It also includes music that was previously released by major or independent recording companies but is no longer available from them in material form, or through legitimately licensed download or streaming channels. These recordings are commonly known as OOP (out-of-print). It is also common to collect library music releases (Rogers 2008; Trunk 2016). These albums were never intended for direct sale to the consumer market when originally manufactured, but were instead sold to other businesses for use on film soundtracks, television shows, commercials and so on. All of these forms of recorded music are shared for free by fans and collectors through websites, blogs, cyberlockers and so on in a practice termed "sharity" (which conflates the words "share", "rarity" and "charity"; see Reynolds 2008, 2011), and there is often specialisation by genre, style, geography or era, with uploaders sometimes providing descriptions and reviews of the music they have made available for download.

There are some parallels between the activities discussed in this article and the broader practices of community-led archivism that have previously been examined in relation to place-placed cultural heritage projects (for example, Baker 2015; Bennett 2009; Cohen et al. 2014). Roberts and Cohen (2014) suggest a tripartite definition of heritage discourse: officially authorised, self-authorised and unauthorised. Each of these three types is ascribed with value and legitimacy through a variety of processes and practices. Officially authorised heritage is often state-sanctioned and supported, while self-authorised heritage receives only 
limited state support and is typically sustained by the enterprise and energy of enthusiasts and volunteers. Baker and Huber (2013) refer to self-authorised heritage projects such as museums, archives and halls of fame as "DIY institutions", and these may be contrasted with online community archives, such as fan shrines and social media sites focused on particular artists, genres or scenes, which seek no authorisation and may not even conceive of themselves as archives (Baker and Collins, 2015: 986-987). In Roberts and Cohen's (2014) definition, these online community archives would be described as unauthorised heritage, and the two fan practices discussed in this paper would also fit into this category since validation is received primarily from other music fans, and for the most part they operate outside official music industry frameworks and copyright legislation.

\section{Methodology}

It is not the intention of this article to justify or condone the practices and actions of the fans, collectives and blogs that it discusses, but to investigate those practices in order to understand the nature of music collecting as it has moved to an online environment. Data collection for this article followed a similar methodology to that employed by Nieckarz (2005) in that it involved the observation and archiving of the online activities of not-for-profit bootleggers and bloggers over a number of years. The websites and blogs involved are (or were) publicly available to view, in that they required no passwords or membership details to access and read them, and those in a blog format had accessible archives organized chronologically, which meant that past posts could be accessed in the order in which they were made. The music blogs and sites identified through initial research led to a plethora of other sites through the use of blogrolls - automatically updating weblinks that are hosted by one blog, but link directly through to others. Through this process it was found that news stories circulating in 2012 about the imminent demise of rare and obscure MP3 blogs were somewhat premature (Allen 2012; Newton 2012a, 2012b; Staley 2012), though the reasons behind these stories bear further investigation and will be discussed below. Nieckarz drew on the work of Fox and Roberts (1999) to argue that material posted on freely accessible websites can be quoted because these sites act as public forums and "anything said was done so in the frame of mind that it would be a public statement" (Nieckarz 2005: 408). However, for this article, a more circumspect approach has been adopted since the activities under scrutiny infringe the terms of copyright legislation such as the US Copyright Act 1976 (and subsequent amendments), and the UK Copyright Designs and Patents Act 1988. For this reason, the attitudes, motivations and understandings publicly expressed by bloggers and fans in their online posts have been presented in such a way as the individuals involved cannot be directly identified. 


\section{Not-for-profit bootlegging}

Commercial (for-profit) bootlegging has long been a part of the music industry, with the first vinyl bootleg (Bob Dylan's Great White Wonder) appearing in 1969 (Heylin 1995; Lewis 2006). Ever since the 1970s, a key issue for fans interested in collecting live recordings was the inconsistent quality of the commercial bootlegs on offer. This was initially addressed by artist fanzines that listed and reviewed them, and by publications such as Kurt Glemser's Hot Wacks (from 1975) and special features in Record Collector magazine (which launched in 1979). Once the Internet became more broadly available in the 1990s, similar listings, typically based around specific artists, were created online by fans, and these have helped to further promote the collection of bootlegs as a fan activity by providing information, reviews, quality ratings, and notes about variations and alternatives. These archival listings often encompass both commercial and not-for-profit forms of bootlegging, thus becoming key resources on the availability of all non-official live recordings of a chosen artist. In this sense, fans involved in trading and listing activities are acting in much the same ways as the Swedish music fans studied by Baym and Burnett (2009) who served as "active filters" in the sorting, labelling and annotation of cultural materials for the benefit of others.

Not-for-profit bootlegging, known as tape-trading, emerged in parallel with the commercial bootleg market, with fans of the Grateful Dead pioneering the concept and being encouraged by the band to record and trade tapes for free between each other. In early forms of tape trading, fans would swap concert recordings on compact cassette tape and use the postal service for distribution worldwide. Unfortunately, the analogue copying process often led to the circulation of relatively poor quality audio recordings, and it could be difficult to know the quality of a particular tape prior to receipt. This was because tapes would be repeatedly copied from cassette to cassette, leading to a generational loss of audio fidelity with each subsequent copy. One method to overcome this was the "tape tree" - a form of distribution in which an originator (or seed) of a tape would record multiple first generation cassettes from the master recording for distribution to a number of branches. These branches would then copy and distribute the tape to everyone on their mailing list. The emergence of digital audio tape (DAT) in the 1980s and then recordable compact discs (CD-R) in the 1990s solved the problem of generational loss, yet the "tree"-system continued to be used as a convenient and efficient distribution method (Anderton 2006: 166167; see also Watson 1997). Some fans became collectors of both commercial bootlegs and not-for-profit bootlegs in much the same way as they had for the officially released products of the music industry (Heylin 1995; Marshall 2005; Schwartz 1995). In addition, it was not uncommon for fans to copy and trade commercial bootlegs between each other so that those who could not afford or find the original bootlegs, which were usually short-run products of perhaps 500 copies at most (see Marshall 2003, 2005), would be able to access and hear them. This practice presages changes that have been seen in more recent years as collectors shift to online methods of distribution and collection, and is comparable with Shuker's findings that some younger CD collectors were happy to collect reissues rather than valorise original pressings on either CD or vinyl (2010: 74). It is also consonant with Barbrook's notion of a "high tech gift 
economy" in which people "collaborate with each other without the direct mediation of money and politics" (1998: web source), and with the "participatory culture" of Web 2.0 "in which user-generated content stands alongside professionally produced content in claiming audience attention" (Baym and Burnett 2009: 434; see also Jenkins 2006). However, as noted above, these practices have existed since the 1970s, so are less a phenomenon of the Internet than a creative use of it to enhance and simplify free distribution through cyberlockers, BitTorrent links, FTP (File Transfer Protocol) connections, and audio uploads to video sharing sites such as YouTube.

The distinction between commercial and not-for-profit bootlegs, and the blurring between them in terms of audio content has led to the use of the term RolO: Recordings of Illegitimate (or Indeterminate) Origin. Writing in the Pink Floyd webzine Spare Bricks, McInnis (2006: web source) suggests that the term was created by the Echoes discussion list in early 1992 to help separate not-forprofit trading from commercial bootlegging. This implies an acknowledgement of relevant copyright laws - that all unauthorized recording and distribution represents an infringement of copyright - but also demonstrates an ethical stance commonly seen amongst tape-traders: that while they may respect copyright as the means by which their favourite artists earn income, they also regard the free distribution of otherwise unavailable live recordings as essentially harmless to the artist since no profit is being made through the trading process. This stance suggests a misunderstanding of the income routes available through copyright (such as publishing royalties related to songwriting), yet also leads traders to be highly protective of their artists and the not-for-profit bootlegs that fan groups distribute. For instance, when both not-for-profit and commercial bootlegs appear on auction sites such as eBay, many fans will report those sales listings in order to have them removed. Furthermore, fan-created trading groups typically offer guidelines about what is or is not acceptable for trade, and also urge fans to purchase all officially available product prior to engaging in trading activity. This is somewhat contrary to Neumann and Simpson's (1997: 339) suggestion that traders are motivated by the illicit appeal of an anti-commercial and antiestablishment activity that flaunts the copyright rules and ownership of the traditional record industries. Instead, it points to the idea that those involved in these activities should be characterized as highly engaged fans who are seeking to heighten their understanding of an artist's musical creativity, development and personality through appreciation of their live performances (Anderton 2006; Marshall 2005).

Fan-led remaster projects emerged in the late 1990s and early 2000s, as the processing and storage capabilities of home computers rapidly increased and a range of affordable audio correction tools and mastering software was released to the general public together with more sophisticated desktop publishing applications. Recordable CD drives also became a standard accessory for home computing whilst Internet connection speeds and usage began to rise. Together, these created the ideal conditions for fans to take greater control over the production and dissemination of live concert recordings. Some fans and collectives launched remaster projects aimed at sourcing the highest generation copies of live recordings that they could find (preferably the original cassette 
recordings made of a concert), and using the newly available software to enhance the audio content. The aims of these projects are perhaps best summed up by the Progressive Rock Remaster Project (PRRP) whose online mission statement held:

[We aim to] preserve, restore and enhance these recordings as much as possible. Many ... were stored on cassette tape or LP and converted to CD many years ago. The original sources still exist and modern digitization equipment can often capture subtleties within the music previously missed (PRRP n.d.: web source).

These highly knowledgeable fans can identify otherwise unknown recordings by reference to pre-existing exemplars, concert lists and fan reports, and can use the remastering process to heighten the quality and completeness of the various source recordings available. Their enhancements include speed correction, equalisation, the removal of background hiss, and the splicing of separate recordings to replace audio drop-outs caused by user error, tape flips or incomplete tapes. In doing so they create alternative canons of recordings that exist alongside official canons, but may tell very different stories about the development of an artist from the perspective of their otherwise undocumented live performances.

The success of such groups led original tapers and those in possession of unique and otherwise uncirculated recordings to come forward and share their tapes with those managing the projects. For instance, the Tangerine Tree project, which ran from 2002 to 2006, unearthed first generation tapes of concerts by the German electronic music pioneers Tangerine Dream that had only previously been available in much poorer versions. Such was the quality of these recordings that the band subsequently used the CD-Rs created by the Tangerine Tree project as the basis of a number of officially released archival releases (Anderton 2006: 173). It has also spurred many record companies into releasing archival recordings themselves in order to cater to (or capture) the heritage or nostalgia market that has grown in recent years for artists active in live performance during, in particular, the late 1960s and 1970s. Artists such as Yes, Pink Floyd, Led Zeppelin, Genesis, Frank Zappa, King Crimson, Jethro Tull and many others did release live albums during the 1970s, but many of their tours and performances were not well represented by official releases at the time, hence the strong fan interest in acquiring bootleg live recordings.

Fan-led remaster projects (such as Hogweeds, PRRP, the Tangerine Tree and the Zappateers) would often package their not-for-profit recordings with cover art, logos, photographs and liner notes, thus mirroring both the commercial bootleggers and the products of the official recording industry. They even developed consistent branding and design aesthetics which would offer reassurance to fans as to the quality of the recordings contained within. It is these characteristics that lead me to term such projects as pseudo-record labels, due to the level of organisation they demonstrate and the record label functions they undertake: from the sourcing, curation and (re)mastering of audio recordings to their subsequent packaging, distribution and marketing to like-minded fans. One of the earliest of these not-for-profit pseudo-record labels was Harvested Records, established by Ron Toon in 1998. Toon was an avid bootleg collector who had 
previously provided tapes and liner notes for an Italian commercial bootleg company called Great Dane Records that had made use of a short-lived European copyright loophole to produce CD bootlegs legally (see Heylin 1995; Marshall 2005). Toon was not impressed with the quality control of Great Dane Records, and was also concerned about the legality of commercial bootleg CDs, so he set up Harvested Records to produce, package and distribute his recordings to other Pink Floyd fans entirely for free (Toon 2006: web source). The website listed nearly 40 titles by the time the project came to a close and stated that "None of these titles are for sale and we highly discourage the practice. What we are trying to establish is for our work to be freely shared amongst fans without asking anything in return" (Harvested n.d.: web source). Variants of this sentiment were printed on the artwork produced by many other remaster projects including the Tangerine Tree and PRRP: "Produced by fans for fans. Trade freely but never buy or sell" (PRRP n.d.: web source).

Support for the not-for-profit ethical position is given by many artists who view trading as a good way for fans to interact with each other and maintain interest in the activities of the artist between official releases and tours. As noted earlier, the Grateful Dead were probably the first band to see the potential of not-for-profit trading, but many others are now known to be trade-friendly - ranging from the numerous American jam bands that followed in the wake of the Grateful Dead (such as Sound Tribe Sector Nine, moe., Umphrey's McGee and The String Cheese Incident) to singer-songwriters and musicians such as Keller Williams, Josh Ritter and Mike Keneally. As trade-friendly artists, they explicitly or implicitly condone the practice, provided that no money is being made by those involved. A list of trade-friendly artists can be found at etree.org and at the Internet Archive which offers the free download of over 150,000 concert recordings (Etree.org 2016). Some artists, such as Phish, also offer special taping sections at their concerts where fans can set up their recording equipment and gain a highly quality audio recording than if they surreptitiously recorded the concert from within the crowd (Phish 2013: web source). Interestingly, Phish now runs its own live concert subscription streaming service (livephish.com), which helps to foster fan-artist cohesion as well as to support the band financially, whilst still offering "taper tickets" so that fans can record the concerts themselves should they wish to (Phish 2016).

However, not all artists are trade-friendly in this manner, and while trading is often seen as ethically sound as long as it does not result in profits, the majority of not-for-profit trading activity technically represents an infringement of copyright legislation since permission to record, duplicate and distribute has not been given by relevant copyright holders, such as music publishers. One notable case of an artist who is unhappy with bootlegging of any sort is Robert Fripp, who seeks to control and present his own musical works, and those of his bands such as King Crimson, on his own terms. Nevertheless, the growth in trading has benefited artists such as Fripp, since he requested that fans send in their bootlegged recordings to his record company Discipline Global Mobile (DGM). Several of these recordings have since been remastered by DGM and integrated into the official release of a number of retrospective and archival boxsets and CD releases (see Atton 2014). 


\section{Obscure music blogs}

Blogs first emerged in the mid-1990s and can be described as a form of online diary with a typically informal and individualistic style (Jetto 2014: 62), though they may also be maintained and updated by multiple users working in collaboration. MP3 blogs first appeared in the aftermath of court action taken against the peer-to-peer service Napster (see David 2009 for a full discussion of the legal case), with Fluxblog being one of the first. Launched in February 2002 Fluxblog offered daily music reviews in addition to providing time-limited download links to individual tracks (Newton 2012a: web source; Perpetua n.d.: web source). At this time, MP3 blogs were primarily focused on discussing newly released music and thus acted, in part, as independent tastemakers promoting the music which most excited the blogs' authors (see Goldstone 2006; Jetto 2014). While many of the more popular blogs have since gone on to be co-opted by music industry marketers keen to exploit the subcultural cachet and authenticity of these supposedly independent blogs for promotional purposes (see Jetto 2015; Staley 2012), another form of blog began to appear in 2006 and 2007: the obscure music blog (Allen 2012).

Obscure music blogs allow fans to download the audio content of entire albums, cassettes or singles which are otherwise unobtainable through legitimate primary sources. In other words, they are not available for purchase from the record company, artist or retail stores (physical or online), nor for access through a legitimate streaming audio service. This may be because the record company involved has allowed a recording to go out of print, or because the record company no longer exists and ownership of its catalogue of recordings is unknown. It may also be that the recordings were originally issued as private press releases by the artist, so have never had widespread distribution or been assigned to a record company for distribution and sale. Straw (2000a, 2000b) refers to outof-print recordings in particular as "obsolete objects" and "exhausted commodities" which persist in physical form long after their initial commercial life cycle and economic value has passed. Nevertheless, these physical artefacts may gain new value as collector's items, with some collectors willing to pay substantial sums in order to gain ownership of them (see Shuker 2010). Straw (2000a) argues that the collection of outdated products of the past has a tendency to level out the differences in prestige and ambition that had originally led them to become obsolete, hence leading to a recasting of perceptions and of value. In the case of obscure music blogs we can see the intersection of fans' secondary involvement (Shuker 2014) in sourcing and collecting rare recordings, and the tertiary involvement of fans who download digitized audio files made from those recordings. McCourt (2005: 250) suggests that while digitized music files lack materiality, they may also heighten a sense of "ownership" and offer different forms of "intense and intimate experience" based around the ability to easily store, access and customize collections on hard drives. This links to the appeals and motivations found among record collectors in Shuker's work, where collection size, accumulation, completism, selectivity and discrimination were all found to be important drivers (2014: 172-174). This sense of ownership may well be challenged in the future as access models continue to grow in importance, and 
new digital devices push consumers further towards the use of cloud-based services (Wikström 2009, 2012).

It is common to find obscure music blogs which are curated around specific genres or styles of music, or specific record labels, eras or types of music production. Examples include blogs devoted to garage rock, progressive rock, heavy metal, industrial, free jazz, afrobeat, and easy listening, space age lounge and exotica, to geographically bounded or localized folk, punk, and rock scenes, and to record labels such as the library music producer KPM Music or the output of the $\mathrm{CTI} / K u d u$ and MPS jazz labels. There are also blogs which curate and distribute soundtrack albums, compilation albums, 12" dance remixes, and ambient electronic music released as private press cassette tapes. In addition to providing download links and cover art, fans may also write descriptions and reviews of the music, provide short histories of the artists, or offer their own personal commentaries about the place of the music in their lives. In doing so, it may be argued that these bloggers are acting as informal cultural historians or archaeologists engaged in uncovering, discussing and contextualizing the music and artists concerned. They may also foster or support specific musical subcultures or taste communities and come to resemble a version of the Internetbased "silo cultures" identified by Condry (2006), where information about an artist or genre is obsessively collected on a single website (see also Baker 2015; Cohen et al. 2014). Furthermore, online interactions between bloggers and their visitors, or between different bloggers who share similar music interests, might constitute a loose version of what Rheingold (2000) has called "virtual community". However, there are also visitors who do little more than download the music they seek without leaving comments to thank the blogger for making the music available. Some bloggers have counteracted this by requiring that sufficient requests are made in the comments section of a post prior to making a download link available. However, this seems to be relatively rare, and the Internet rhetoric of "information wants to be free" usually leads to free and open sharing. This is in contrast to early versions of MP3 trading through Internet Relay Chat (IRC) networks in the 1990s, where exchange ratios were imposed to ensure that downloaders also uploaded music back to the network in order to continue to download (see Cooper and Harrison 2001; Leyshon 2003; Slater 2000). Enhanced Internet connection speeds and the proliferation of distribution methods means that such demands are now less commonplace.

Interestingly, the second-hand purchase and sale of a physical music artefact such as a vinyl album does not constitute an infringement of copyright legislation under European or American copyright legislation, even though the copyright owners (artists, publishers and record labels) will gain no financial reward from the sale (Anderton et al. 2013: 163-164). This is because there is no copying taking place when ownership of a physical artefact is transferred. In contrast, when an intangible audio file (MP3, FLAC, OGG, WAV and so on) is either uploaded to, or downloaded from, the Internet, each process is technically an act of copying, hence there is infringement of both the distribution right and the reproduction right under copyright law, since the authorisation of the copyright owners has not been sought (see Goldstone 2006: 4-9). Yet, the rarity of the tracks being distributed through obscure music blogs means that they typically have a 
low profile and are therefore unlikely to be subject to direct legal action by copyright owners (Goldstone 2006: 36). That is not to say, however, that this does not happen. Indeed, some bloggers have seen their accounts suspended for Terms of Service breaches after copyright holders complained directly to the blogging platform. For instance, one blogger reported an occasion when a complaint had been received following the upload of an album which included a cover version of a song originally written by a well-known popular music act. It was, therefore, the publisher of that song who made the complaint, even though the recording uploaded was a private press release by a relatively unknown band. As the Terms of Service for operating a blog typically contain a clause stating that the blogger will not knowingly upload copyrighted material for distribution to others, this is one route through which copyright owners can take action. As a result, it is common to see statements on obscure music blogs which confirm that any music they upload will be removed upon request of the copyright owner.

Another threat to obscure music blogs is legal action taken against cyberlockers, since these large file-transfer services have been targeted by music industry representatives for their role in distributing pirated music online. Many obscure music blogs make use of these cyberlockers, so when pressure is placed through the use of takedown notices issued under the 1998 US Digital Millennium Copyright Act (DMCA), or through the shuttering of a cyberlocker service such as MegaUpload in January 2012 (see Anderton et al. 2013: 176-177), there are knock-on effects for blog owners (see also Baker and Collins 2015). For instance, following the MegaUpload case, a number of other cyberlocker sites altered their terms and conditions to prevent their use as distribution hubs for bloggers. This meant that download links archived on those blogs became inaccessible, leading some bloggers to retaliate by re-uploading their archives to alternative services which continued to allow downloading by multiple anonymous users. In some cases, blogs had their links removed two or three times, leading the owners of those blogs to stop blogging altogether, though their sites have been left online as archive resources. Notably, DMCA takedown notices do not require a court order or lawyer to be generated by music industry representatives, so they may be repeatedly issued. The height of this music industry activity was 2012, which led several online commentators to suggest that obscure music blogs would soon be a thing of the past, since some well-known bloggers of the time had stopped providing full album download links or ceased posting altogether (Allen 2012; Newton 2012b). This proved not to be the case, since fans continue to create new obscure music blogs and to distribute music that has, in their view, been ignored by the music industries. It may be that these blogs largely avoid the attention of the music industries due to the nature of the material they are distributing (rare and private press releases of the past). The record companies are, instead, more intent on targeting blogs which offer downloads of leaked pre-release albums and singles, and of more commercially valuable artists and genres.

Reading through numerous blogs shows that there is relatively little public discussion of copyright law by bloggers and their visitors, though there are occasional discussions within the comments sections of their posts. These sections demonstrate a persistent belief or justification that, as seen earlier in the case of not-for-profit bootleg trading, the lack of monetary gain and the commercial 
unavailability of the music mean that there should be no reason not to post download links. Instead, bloggers make aesthetic and democratic justifications for their activities online (see also Baker and Collins 2015). Aesthetic because music is being saved and promoted that would otherwise be lost and democratic because more people will have the opportunity to hear this music, rather than just the few who were able to purchase what are now rare items when they were initially released, or who can find and afford to buy those rare items on the second-hand market. It may be argued that they are acting both as cultural intermediaries (Negus 1992) between artists and listeners, and as sonic archivists who seek to curate niche musical histories. This is akin to what Bennett has termed "DiY preservationism" (2009: 474), in which individuals or groups of individuals embark on a grassroots effort to give value to, or "consecrate" (see Dowd et al. 2016: 97), artists and genres that usually lie beyond mainstream media histories of the development of popular music (see also Baker 2015; Baker and Collins 2016; Bennett 2009; Cohen et al. 2014;). As Straw has noted of physical record collectors, these fans are "engaged in an ongoing enterprise of vernacular scholarship" (2000b: 168), and the connections between physical and online collectors are enhanced by the publication of discographies and encyclopaedias of rare and obscure music genres and scenes which drive an urge towards collection and completism. The sheer volume of material covered by these publications means that traditional physical collecting is often too costly for fans, hence the attraction of blogs where they can hear music that they might otherwise have been unable to afford to buy.

\section{Conclusion: fan labour and precarious archivism}

The cultural work of the fans discussed above is voluntary and non-monetary in nature, yet implicated in various kinds of labour. For instance, there is the material labour of bootleg production such as the sourcing and remastering of recordings, creating artwork, and managing distribution. There is also material work and equipment involved in sourcing and digitizing recorded music artefacts and the financial and time costs associated with writing blog posts, managing blog sites and cyberlockers, and responding to visitor requests. Alongside this material work is what Lazzarato has called "immaterial labour", defined as the production of the "informational and cultural content of the commodity" (1996: 132). This can be seen in the curatorial activities of both bloggers and remaster groups, as can "affective labour" (Hardt 1999: 89), which can refer to the social production of collective subjectivities and knowledge such as through fan interactions on message boards or in the comments sections of blog posts. In these places it is possible to find not only discussions about the availability and quality of various recordings and releases, or additional information that clarifies the origins of the music, but also stories about fans' own experiences of the music being shared, or of the local scenes and musicians that that music was originally a part. Terranova (2002, 2004) collectively refers to such material, immaterial and affective labour as "free labour", described as "the moment where this knowledgeable consumption of culture is translated into productive activities that are pleasurably 
embraced and at the same time often shamelessly exploited" (Terranova 2000: 37).

Terranova's (2000) warnings of exploitation have some echoes within the remaster and tape trading world, since artists (and their commercial representatives) who condone the practice are allowing fans to engage in a pleasurable and social activity which nevertheless has marketing implications and value. For instance, fans from disparate parts of the world are encouraged to remain actively engaged in the ongoing work of the artist, and to buy an artist's entire extant catalogue or attend their concerts when possible. As noted above, the ongoing trade in not-for-profit bootlegs can help to foster a ready-made market for official archive releases even where the audio material itself has previously been shared in bootleg form (see also Anderton 2006; Marshall 2004). Traditional structures of commercial exploitation and copyright are, therefore, actually reinforced through not-for-profit bootleg trading. Nevertheless, traders voluntarily offer their free labour because they feel that they gain from their involvement. For instance, as Marshall (2003) suggests, there is an aesthetic pleasure in hearing a favourite artist performing live, perhaps with one-off performances of otherwise unreleased songs or versions and arrangements which differ from official releases. Extended to the level of genre and the activities of bloggers, we can argue that fans are educating themselves in an otherwise hidden history of music. Moreover, they are engaging in curatorial work which has become democratized through the mediation of the Internet, since recordings which would have been difficult to obtain in the past are now more readily available through free download links.

However, the activities of the obscure music bloggers in particular offer only a rather precarious form of sonic archivism (see also Baker and Collins 2015, 2016 on the sustainability of community archives). The free labour of the bloggers is not, as noted above, truly free, and it is not uncommon for bloggers to run out of steam after a while or for blogs to become dormant and links unavailable. In addition, these activities take place within the public sphere of the Internet and so are subject to music industry surveillance activities, as noted above. In such an environment, the stability of the sonic archives being created by bloggers is weak since the download links and cyberlockers that they rely on can be easily deleted. This promotes the downloading and stockpiling of music files by visitors, which constitutes tertiary involvement through a virtual form of ownership and through the creation of privatized rather than public silos or archives. This privatisation of the archive into personalised collections is tempered by a continuance of sharity practices (Reynolds 2008, 2011) as new blogs are established and recordings shared once again in a circuit of temporary availability.

Writing in 2011, Rojek suggested that a "second enclosure movement" had emerged online, driven by a combination of corporate industry and state institutions. In essence, he argued that the previously open and democratic public sphere of the Internet had become increasingly privatized by the music industries, and that the music industries and the state worked together to reinforce current copyright regimes by reducing debate regarding possible alternatives (Rojek 2011: 216; see also Boyle 2003). Similarly, Burkhart argues that the music industries enjoy "state-sanctioned monopolies, and the policing power to enforce them" (2010: 1). Actions against cyberlockers and music piracy in general continue, yet 
there is also a push towards legitimizing models of music licensing through streaming audio sites. In this model, music fans and consumers are redefined as music users who no longer own recordings, but merely access streaming music for a subscription fee or in return for viewing advertising. Under such a model, the activities of online archivists could become ever more marginalized since the "obsolete" music objects that interest them (private press releases, live bootlegs and other rarities) are unlikely to be made available as streams due to uncertainties over copyright ownership and licensing. Yet, this also makes their activities important in terms of the preservation of, and access to, musical history, since there is otherwise a danger of them being lost from circulation altogether.

The cultural work, or free labour, of fans is considerable, and the tertiary engagement of sharing, promoting and owning digitized music files of obscure, rare and difficult-to-find recordings will continue because so much music still lies outside of Anderson's (2006) "Iong tail" economics. Fan practices which began offline and largely beyond the control of the music industries have, in the process of shifting to online methods, become subject to increasing surveillance and legal action by the music industries, thus jeopardizing the fragile archiving activities of fans. If the music industries have, as Burkhart (2010) and Rojek (2011) suggest, sought to legitimize and normalize existing regimes of copyright law and ownership in the Western world, then the public good clauses of US and European copyright law come into question. Copyright law gives legal protection to copyright owners for a set period time: when that time has expired, the work passes into the public domain and becomes a collectively owned and shared cultural asset available for use by anyone (Anderton et al. 2013: 164). Arguably, it is under this latter justification that fans share material that is not otherwise commercially available from legitimate sources: in doing so, they are contributing to cultural life and freeing the music from a form of contractual and copyright limbo that might cause the music disappear from circulation altogether.

This article has only begun to chart the breadth of motivations, practices and implications of the fan activities that it focuses upon, and of fan understandings of copyright law in relation to them. Nevertheless, it suggests that collecting continues to be premised on a form of ownership which is predicated on control: the storage and distribution of music that cannot otherwise be obtained through legitimate means or only through the second hand market. It also suggests that valorization of rarity continues to be important, even in an online environment which allows global distribution of the digitized files. Future work in this area might look at the effect of these shifts on the second hand physical market, or examine further the practices, motivations and understandings of those engaged in tertiary, rather secondary involvement.

\section{References}

Allen, M. 2012. The Rise and Fall of the Obscure Music Download Blog: A Roundtable. The Awl 27 November. http://www.theawl.com/2012/11/the-rise-and-fall-of-obscure-music-blogs-aroundtable; Accessed: 1 February 2016. 
Anderson, C. 2006. The Long Tail: Why the Future of Business Is Selling Less of More. New York: Hyperion.

Anderton, C. 2006. Beating the Bootleggers: Fan Creativity, "Lossless" Audio Trading, and Commercial Opportunities. In M. D. Ayers Ed. Cybersounds: Essays on Virtual Music Culture. New York: Peter Lang: 161-184.

Anderton, C. et al. 2013. Understanding the Music Industries. London: Sage.

Atton, C. 2014. Curating Popular Music: Authority and History, Aesthetics and Technology. Popular Music 33 (3): 413-427. http://dx.doi.org/10.1017/S026114301400035X

Baker, S. Ed. 2015 Preserving Popular Music Heritage: Do-it-Yourself, Do-itTogether. London and New York: Routledge.

Baker, S. and Collins, J. -

2015. Sustaining Popular Music's Material Culture in Community Archives and Museums. International Journal of Heritage Studies 21 (10): 983-996. http://dx.doi.org/10.1080/13527258.2015.1041414

2016. Popular Music Heritage, Community Archives and the Challenge of Sustainability. International Journal of Cultural Studies. Published online before print on March 9, 2016. http://dx.doi.org/10.1177/1367877916637150

Baker, S. and Huber, A. 2013. Notes Towards a Typology of the DIY Institution: Identifying Do-it-Yourself Places of Popular Music Preservation. European Journal of Cultural Studies 16 (5): 513-530. http://dx.doi.org/10.1177/1367549413491721

Barbrook, R. 1998. The High-tech Gift Economy. First Monday 10 (special issue 3). http://firstmonday.org/article/viewArticle/1517/1432; Accessed: 1 February 2016.

Baym, N. and Burnett, R. 2009. Amateur Experts: International Fan Labour in Swedish Independent Music. International Journal of Cultural Studies 12 (5): 433-449.

http://dx.doi.org/10.1177/1367877909337857

Bennett, A. 2009 "Heritage Rock": Rock Music, Representation and Heritage Discourse. Poetics 37 (5/6): 474-489. http://dx.doi.org/10.1016/j.poetic.2009.09.006

Bennett, A. and Rogers, J. 2016. Popular Music and Materiality: Memorabilia and Memory Traces. Popular Music and Society 39 (1): 28-42. http://dx.doi.org/10.1080/03007766.2015.1061339

Boyle, J. 2003. The Second Enclosure Movement and the Construction of the Public Domain. Law and Contemporary Problems 66 (1/2): 33-74. http://scholarship.law.duke.edu/lcp/vol66/iss1/2; Accessed: 1 February 2016.

Burkart, P. 2010. Music and Cyberliberties. Middletown, CT: Wesleyan University Press.

Cohen, S. et al. Eds. 2015. Sites of Popular Music Heritage: Memories, Histories, Places. London and New York: Routledge.

Condry, I. 2006. Hip-Hop Japan: Rap and the Paths of Cultural Globalization. Durham, NC: Duke University Press.

Cooper, J. and Harrison, D. M. 2001. The Social Organization of Audio Piracy on the Internet. Media, Culture and Society 23 (1): 71-89.

http://dx.doi.org/10.1177/016344301023001004 
David, M. 2009. Peer to Peer and the Music Industry: The Criminalization of Sharing. London: Sage.

Dowd, T. J. et al. 2016. Talk of Heritage: Critical Benchmarks and DIY

Preservationism in Progressive Rock. Popular Music and Society 39 (1): 97-125. http://dx.doi.org/10.1080/03007766.2015.1061354

Duffett, M. 2013. Understanding Fandom: An Introduction to the Study of Media Fan Culture. New York: Bloomsbury Academic.

Etree.org 2016. Live Music Archive [hosted by the Internet Archive]. https://archive.org/details/etree; Accessed: 1 February 2016.

Fox, N. and Roberts, C. 1999. GPs in Cyberspace: The Sociology of a "Virtual Community". The Sociological Review 47 (4): 643-671. http://dx.doi.org/10.1111/1467-954X.00190

Goldstone, A. 2006. MP3 Blogs: A Silver Bullet for the Music Industry or a Smoking Gun for Copyright Infringement? Social Science Research Network. http://dx.doi.org/10.2139/ssrn.930270

Hardt, M. 1999. Affective Labor. Boundary 226 (2): 89-100. http://www.jstor.org/stable/303793; Accessed: 1 February 2016.

Harvested. n.d. Harvested Records [site archived by the Internet Archive]. https://web.archive.org/web/20110903085934/http://www.harvested.org; Accessed: 1 February 2016.

Heylin, C. 1995. Great White Wonders: A History of Rock Bootlegs. London: Penguin Books.

Hu, C. 2015. How Music Streaming is Creating a New Type of Superfan. Forbes.com, 10 November.

http://www.forbes.com/sites/cheriehu/2015/11/10/how-music-streaming-iscreating-a-new-type-of-superfan/\#3af21fca6331; Accessed: 1 February 2016.

IFPI. 2015. IFPI Digital Music Report 2015: Charting the Path to Sustainable Growth. http://www.ifpi.org/downloads/Digital-Music-Report-2015.pdf Accessed: 1 February 2016.

Jenkins, H. 2006. Convergence Culture: Where Old and New Media Collide. New York: New York University Press.

Jetto, B. -

2014. Music Blogs and the Music Industry: Collusion or Independence? International Journal of Music Business Research 3 (2): 60-80. https://musicbusinessresearch.files.wordpress.com/2012/04/volume-3-no-2october-2014_jetto_end.pdf; Accessed: 1 February 2016.

2015. The Evolution of Music Blogs: From a Fan's Passion to a Promotional Outlet. International Journal of Music Business Research 4 (2): 49-72. https://musicbusinessresearch.files.wordpress.com/2012/04/volume-4-no-2october-2015-beatrice-jetto.pdf; Accessed: 1 February 2016.

Klein, B. et al. 2015. Understanding Copyright: Intellectual Property in the Digital Age. London: Sage.

Lazzarato, M. 1996. Immaterial Labor. In P. Virno and M. Hardt Eds. Radical Thought in Italy. Minneapolis: University of Minnesota Press: 132-146.

Lewis, G. H. 2006. Some of These Bootleggers, They Make Pretty Good Stuff: Love and Theft from the Dylan Underground. Popular Music and Society 29 
(1): 109-120.

http://dx.doi.org/10.1080/03007760500167453

Leyshon, A. 2003. Scary Monsters? Software Formats, Peer-to-peer Networks, and the Spectre of the Gift. Environment and Planning D: Society and Space 21 (5): 533-558.

http://dx.doi.org/10.1068/d48j

Marshall, L. -

2003. For and Against the Record Industry: An Introduction to Bootleg

Collectors and Tape Traders. Popular Music 22 (1): 57-72.

http://dx.doi.org/10.1017/S0261143003003040

2004. The Effects of Piracy Upon the Music Industry: A Case Study of

Bootlegging. Media, Culture and Society 26 (2): 163-181.

http://dx.doi.org/10.1177/0163443704039497

2005. Bootlegging: Romanticism and Copyright in the Music Industry. London: Sage.

McCourt, T. 2005. Collecting Music in the Digital Realm. Popular Music and Society 28 (2): 249-252.

http://dx.doi.org/10.1080/03007760500045394

McInnis, M. 2006. What's in a Name? The Origins of the "RolO". Spare Bricks:

The Pink Floyd Webzine 29.

http://sparebricks.fika.org/sbzine29/features.html; Accessed: 1 February 2016.

Negus, K. 1992. Producing Pop: Culture and Conflict in the Popular Music Industry. London: Edward Arnold.

Neumann, M. and Simpson, T.A. 1997. Smuggled Sound: Bootleg Recording and the Pursuit of Popular Memory. Symbolic Interaction 20 (4): 319-341. http://dx.doi.org/10.1525/si.1997.20.4.319

Newton, C. 2012a. Spotify, Radio and the Slow Death of MP3 Blogging. Crumbler [blog] 15 March. http://crumbler.tumblr.com/post/19364729631/spotify-rdio-andthe-slow-death-of-mp3-blogging; Accessed: 1 February 2016.

2012b. No, the RIAA Did Not Kill Your Obscure Music Blog. Crumbler [blog],

29 November. http://crumbler.tumblr.com/post/36821590277/no-the-riaa-

did-not-kill-your-obscure-music-blog; Accessed: 1 February 2016.

Nieckarz, P. P. 2005. Community in Cyber Space? The Role of the Internet in Facilitating and Maintaining a Community of Live Music Collecting and Trading. City \& Community 4 (4): 403-423. http://dx.doi.org/10.1111/j.1540-6040.2005.00145.x

Nielsen. 2014. 2014 Nielsen Music U.S. Report.

http://www.nielsen.com/content/dam/corporate/us/en/public\%20factsheets/Sou ndscan/nielsen-2014-year-end-music-report-us.pdf; Accessed: 1 February 2016.

Pearce, S.-

1992. Museums, Objects and Collections: A Cultural Study. Washington:

Smithsonian Institution Scholarly Press.

1995. On Collecting: An Investigation into Collecting in the European Tradition.

London and New York: Routledge.

Perpetua, M. n.d. About Fluxblog. Fluxblog [blog].

http://www.fluxblog.org/about/; Accessed: 1 February 2016. 
Phish. -

2013. Taping Policy [updated 24 October]. http://phish.com/faq/\#tapingguidelines; Accessed: 1 February 2016.

2016. Phish Summer 2016: Ticket Request Types.

http://tickets.phish.com/information/; Accessed: 19 June 2016.

PRRP - Progressive Rock Remaster Project n.d. About PRRP: Mission and Structure of PRRP. http://www.prrp-music.org/about.htm; Accessed: 1 February 2016.

Reynolds, S. -

2008. Sharity Begins at Home: The Whole Album Music Blog Scene. The Wire 297 (November): 46.

2011. Retromania: Pop Culture's Addiction to its Own Past. London: Faber and Faber.

Rheingold, H. 2000. The Virtual Community: Homesteading on the Electronic Frontier. Cambridge, MA: MIT Press. Revised edition.

Roberts, L. and Cohen, S. 2014. Unauthorising Popular Music Heritage: Outline of a Critical Framework. International Journal of Heritage Studies 20 (3): 241 261. http://dx.doi.org/10.1080/13527258.2012.750619

Rogers, J. 2008. The Lost Geniuses of Library Music. The Guardian 29 August. http://www.theguardian.com/music/2008/aug/29/electronicmusic; Accessed: 1 February 2016.

Rojek, C. 2011. Pop Music, Pop Culture. Cambridge: Polity Press.

Schwartz, D. 1995. Strange Fixation: Bootleg Sound Recordings Enjoy the Benefits of Improving Technology. Federal Communications Law Journal 47 (3), article 6. http://www.repository.law.indiana.edu/fclj/vol47/iss3/6: Accessed: 1 February 2016.

Shuker, R. -

2010. Wax Trash and Vinyl Treasures: Record Collecting as a Social Practice. Farnham: Ashgate.

2014. Record Collecting and Fandom. In M. Duffett Ed. Popular Music

Fandom: Identities, Roles and Practices. London and New York: Routledge: 165-185.

Slater, D. 2000. Consumption Without Scarcity: Exchange and Normativity in an Internet Setting. In P. Jackson et al. Eds. Commercial Cultures: Economies, Practices, Spaces. Oxford: Berg: 123-142.

Staley, W. 2012. A Quick Thought on Obscure Music Blogs. I Don't Know, Man [blog] 27 November.

http://willystaley.tumblr.com/post/36687654184/a-quick-thought-on-obscuremusic-blogs; Accessed: 1 February 2016.

Straw, W. -

2000a. Exhausted Commodities: The Material Culture of Music. Canadian Journal of Communication 25 (1).

http://cjc-online.ca/index.php/journal/article/view/1148/1067; Accessed 1

February 2016.

2000b. Music as Commodity and Material Culture. Repercussions 7-8 (Spring-

Fall 1999-2000): 147-172. https://www.ocf.berkeley.edu/ repercus/wp- 
content/uploads/2011/07/repercussions-Vol.-7-8-Straw-Will-Music-as-

Commodity-and-Material-Culture.pdf; Accessed: 1 February 2016.

Terranova, T. -

2000. Free Labor: Producing Culture for the Digital Economy. Social Text 18 (2): 33-58.

http://dx.doi.org/10.1215/01642472-18-2_63-33

2004. Network Culture: Politics for the Information Age. London: Pluto Press.

Toon, R. 2006. Loyalty, History, and Shades of Gray: A Personal History of

Bootleg Recordings. Spare Bricks: The Pink Floyd Webzine 29.

http://sparebricks.fika.org/sbzine29/features.html; Accessed: 1 February 2016.

Trunk, J. 2016. The Music Library. London: FUEL. Revised and expanded edition.

Wall. T. 2013. Studying Popular Music Culture. London: Sage. Second edition.

Watson, N. 1997. Why We Argue About Virtual Community: A Case Study of the Phish.net Fan Community. In S. G. Jones Ed. Virtual Culture: Identity and Communication in Cybersociety. London: Sage: 102-132.

Wikström, P. -

2009. The Music Industry. Cambridge: Polity.

2012. A Typology of Music Distribution Models. International Journal of Music Business Research 1 (1): 7-20.

https://musicbusinessresearch.files.wordpress.com/2012/04/ijmbr_april_201 2_patrik_wikstrom1.pdf; Accessed: 1 February 2016. 